\title{
Aluminium Mobilization from Acidic Forest Soils in Leigongshan Area, Southwestern China: Laboratory and Field Study
}

\author{
J. Guo, ${ }^{1}$ R. David Vogt, ${ }^{2}$ X. Zhang, ${ }^{1}$ Y. Zhang, ${ }^{1}$ H. M. Seip, ${ }^{2}$ J. Xiao, ${ }^{3}$ H. Tang ${ }^{1}$ \\ ${ }^{1}$ Research Centre for Eco-Environmental Sciences, Chinese Academy of Sciences, P. O. Box 2871, Beijing 100085, China \\ ${ }^{2}$ Department of Chemistry, University of Oslo, P. O. Box 1033, Blindern 0315, Oslo, Norway \\ ${ }^{3}$ Guizhou Institute of Environmental Protection Sciences, Guiyang 550002, China
}

Received: 29 December 2003/Accepted: 29 July 2004

\begin{abstract}
Aluminium mobilization from acidic forest soils in the remote Leigongshan area in southwestern China was investigated in the field and by a laboratory batch experiment using sequential extractions with $\mathrm{HCl}$ solutions with $\mathrm{pH}$ of approximately 3.4. Experimental data showed that strongly organically bound aluminium (Alp-Alcu) decreased significantly after sequential extraction, whereas exchangeable aluminium (Alex) increased in all three horizons. In the A-horizon with higher base saturation (BS), dissolved aluminium exchanged with base cations (BCs) on soil complex, causing lower aluminium release but significant leaching of BCs. In AB- and B-horizon with lower BS, more dissolved aluminium remained in solution. $\mathrm{Al}^{3+}$ activities in both experimental soil extracts and field soil waters strongly deviated from those predicted by the gibbsite model (i.e., $\mathrm{pAl}=\mathrm{pKsp}+3.0 \mathrm{pH}$ ) despite a significant increase in $\mathrm{Al}^{3+}$ with a decrease in $\mathrm{pH}$. The soil organic-bound aluminium model, using Alcu and Alp to account for differences in the size of available $\mathrm{Al}$ pools in the soil, gave considerably better fits to both experimental and field data. SOM-Al model, approved by using Alex instead of organically bound aluminium (i.e., Alp and Alcu), could depict the changes in Al activities most successfully. We have concluded that Alp-Alcu is the main source of aqueous aluminium, whereas Alex plays an important role in regulating aluminium solubility during soil acidification.
\end{abstract}

Enhanced dissolution of soil aluminium is one of the most severe effects of acid deposition on a terrestrial ecosystem and an important process by which soils buffer the external $\mathrm{H}^{+}$input. The process consumes $\mathrm{H}^{+}$but increases aluminium concentrations in soil water. Studies in Europe and North America have shown that high concentrations of certain aluminium species could be toxic to both terrestrial vegetation and aquatic organisms (Andersson 1988, Rosseland et al. 1990). Clarifications of the processes that control aluminium release and sol-

Correspondence to: J. Guo; email: guojingheng@vip.sina.com ubility have therefore been regarded as crucial in predicting the impact of acidification on terrestrial and aquatic ecosystems (Mulder et al. 1989; Mulder and Stein 1994; Zhu et al. 1994).

Acid rain has been recognized as a potential environmental problem in China since the late $1980 \mathrm{~s}$, especially in its southern and southwestern parts. In some areas, soil $\mathrm{pH}$ values were reported to have decreased by 0.1 to 1.0 during the course of approximately 30 years, mainly because of acid deposition (Pan 1992; Dai et al. 1998). Later studies in China showed that soil acidification is a major problem in some areas although acidification of surface water is not likely to become a regional problem in the near future (Larssen et al. 1999a; Seip et al. 1999).

The understanding of $\mathrm{Al}$ mobilization mechanisms in acidic Chinese ecosystems is still far from adequate. Based on studies conducted in Europe and North America, models have been developed to simulate the mobilization of aluminium from soils. However, testing these models under Chinese conditions is necessary because of differences in soil, climate, and vegetation between China and these other regions.

In the Leigongshan (LGS) catchment area, located in the remote LGS mountain area in Guizhou province, sulfur deposition is low. Therefore, it was selected as the background site of five IMPACTS (Integrated Monitoring Program on Acidification of Chinese Terrestrial Systems) catchments (Tang et al. 2001). Better understanding of aluminium release and solubility in this pristine catchment has special importance for interpret aluminium solubility in other more acidified soils. Furthermore, there is a lack of such studies in remote areas in China. In this article, Al release mechanisms and solubility in soils were investigated based on IMPACTS field data in 2003 and results from a laboratory experiment using soils collected from the LGS catchment.

\section{Materials and Methods}

\section{Site Description}

LGS, also called Leishan $\left(26^{\circ} 10^{\prime} \mathrm{N}, 108^{\circ} 10^{\prime} \mathrm{E}\right)$, is located approximately $140 \mathrm{~km}$ to the east of Guiyang at an elevation of 
Table 1. Some basic properties of soils in LGS catchment

\begin{tabular}{|c|c|c|c|c|c|c|c|c|}
\hline Soil horizons & $\mathrm{pH}\left(\mathrm{H}_{2} \mathrm{O}\right)$ & $\mathrm{PH}\left(\mathrm{BaCl}_{2}\right)$ & $\begin{array}{l}\text { Organic matter } \\
(\%)\end{array}$ & $\begin{array}{l}\text { CEC } \\
\text { (meq/kg soil) }\end{array}$ & BS (\%) & AlS (\%) & $\begin{array}{l}\text { Alcu } \\
\text { (mmol/kg soil) }\end{array}$ & $\begin{array}{l}\text { Alp } \\
\text { (mmol/kg soil) }\end{array}$ \\
\hline \multirow[t]{2}{*}{ A } & $4.42( \pm 0.03)$ & $3.86( \pm 0.05)$ & $14.5( \pm 1.55)$ & $184.3( \pm 6.65)$ & $31.92( \pm 5.21)$ & $59.8( \pm 7.34)$ & $43.7( \pm 2.89)$ & $92.8( \pm 5.36)$ \\
\hline & $\begin{array}{l}4.07( \pm 0.58) \\
\mathrm{n}=50\end{array}$ & $\begin{array}{l}3.54( \pm 0.58) \\
\mathrm{n}=50\end{array}$ & $\begin{array}{l}11.8( \pm 3.12) \\
\mathrm{n}=50\end{array}$ & $\begin{array}{l}156( \pm 48.7) \\
\mathrm{n}=50\end{array}$ & $\begin{array}{l}52.5( \pm 23.0) \\
\mathrm{n}=50\end{array}$ & $\begin{array}{l}35.0( \pm 17.9) \\
\mathrm{n}=50\end{array}$ & $\begin{array}{l}42.4( \pm 15.6) \\
\mathrm{n}=5\end{array}$ & $\begin{array}{l}95.1( \pm 36.7) \\
\mathrm{n}=5\end{array}$ \\
\hline \multirow[t]{2}{*}{$\mathrm{AB}$} & $4.65( \pm 0.06)$ & $4.24( \pm 0.03)$ & $9.6( \pm 0.47)$ & $55.8( \pm 5.56)$ & $19.08( \pm 3.42)$ & $73.9( \pm 6.31)$ & $23.8( \pm 2.50)$ & $57.2( \pm 4.65)$ \\
\hline & $\begin{array}{l}4.38( \pm 0.56) \\
\mathrm{n}=26\end{array}$ & $\begin{array}{l}3.87( \pm 0.38) \\
\mathrm{n}=26\end{array}$ & $\begin{array}{l}5.89( \pm 3.38) \\
\mathrm{n}=26\end{array}$ & $\begin{array}{l}56.1( \pm 27.3) \\
\mathrm{n}=26\end{array}$ & $\begin{array}{l}43.76( \pm 23.7) \\
n=26\end{array}$ & $\begin{array}{l}50.0( \pm 25.2) \\
\mathrm{n}=26\end{array}$ & $\begin{array}{l}22.3( \pm 10.36) \\
\mathrm{n}=7\end{array}$ & $\begin{array}{l}72.6( \pm 32.1) \\
\mathrm{n}=7\end{array}$ \\
\hline B & $\begin{array}{l}4.81( \pm 0.05) \\
4.39( \pm 0.52) \\
n=20\end{array}$ & $\begin{array}{l}4.45( \pm 0.04) \\
3.96( \pm 0.53) \\
n=20\end{array}$ & $\begin{array}{l}5.5( \pm 0.26) \\
3.34( \pm 1.91) \\
n=20\end{array}$ & $\begin{array}{l}33.9( \pm 3.67) \\
42.5( \pm 29.0) \\
n=20\end{array}$ & $\begin{array}{l}16.16( \pm 1.68) \\
32.5( \pm 28.3) \\
n=20\end{array}$ & $\begin{array}{l}72.9( \pm 2.37) \\
61.7( \pm 26.4) \\
n=20\end{array}$ & $\begin{array}{l}16.5( \pm 3.76) \\
20.2( \pm 7.84) \\
n=6\end{array}$ & $\begin{array}{l}49.0( \pm 3.03) \\
60( \pm 17.4) \\
n=6\end{array}$ \\
\hline
\end{tabular}

For each horizon, the values in the first line are properties of soil samples used in experiment. Data in the second line are median values of available data; number of sample is listed in the third line.

Alcu = Weakly organically bound aluminium.

Alp = Strongly organically bound aluminium.

AlS $=$ Soil aluminium saturation .

$\mathrm{BS}=$ Base saturation.

$\mathrm{CEC}=$ Cation-exchange capacity

approximately 1500 meters. The climate is mild and humid with an annual precipitation of approximately $1300 \mathrm{~mm}$. The annual average temperature is $11.7^{\circ} \mathrm{C}$. In 2000 , the IMPACTS project established a small catchment for integrated monitoring of atmospheric chemistry, precipitation, soil, water, and vegetation. The $\mathrm{SO}_{4}{ }^{2-}$ concentration in precipitation is lower than at the other IMPACTS sites with an annual volume-weighted average of approximately $52.27 \mu \mathrm{mol} \mathrm{L}{ }^{-1}$ in 2003. The annual volume-weighted average $\mathrm{pH}$ for precipitation is approximately 4.44 with lime potential $(=\mathrm{pH}-1 / 2 \mathrm{pCa})$ of approximately 2.13 in the same year. The soil type is yellow according to the Chinese classification system (Haplic Acrlisol in the Food and Agriculture Organisation system). As reported by Lydersen et al. (1997) soil properties vary widely. Some basic soil chemical properties in the LGS catchment are listed in Table 1. The alkalinity of surface water is approximately $88.25 \mu \mathrm{eq} \mathrm{L} \mathrm{L}^{-1}( \pm 37.18$, $n=47$ ), which indicates high sensitivity to acid deposition despite a quite high $\mathrm{pH}$ (Lydersen et al. 1997).

\section{Equipment Installations and Sampling}

The procedures used for equipment installation and sampling of throughfall, litterfall, and soil water in LGS have been described in Vogt et al. (2001). Equipment for soil water sampling was located in four intensive macroplots (i.e., well-defined $10 \times 10 \mathrm{~m}$ squares randomly selected within the watershed) and one additional soil water-only macroplot (Fig. 1). In each of these five macroplots, four soil water lysimeters and four soil temperature sensors were located at different soil depths according to genetic horizons.

Soil water samples from all lysimeters were sampled weekly, and samples for 4 weeks were pooled. Main components were analyzed in a provincial standard laboratory, which was quality approved by the IMPACTS project. In this article, $>100$ soil water samples with ion balance $\left(=\left(\sum\right.\right.$ anion- $\sum$ cations $) /\left(\sum\right.$ anions + $\sum$ cations $\left.* 100 \%\right)<10 \%$ were included. These samples were collected from 15 lysimters located in the A-, AB-, and B-horizons. There were significant temporal and spatial variations in sample composition (Table 2). In addition, soil samples for the A-, ABand B-horizons were collected within the site to conduct laboratory batch experiments after analysis of main soil parameters.

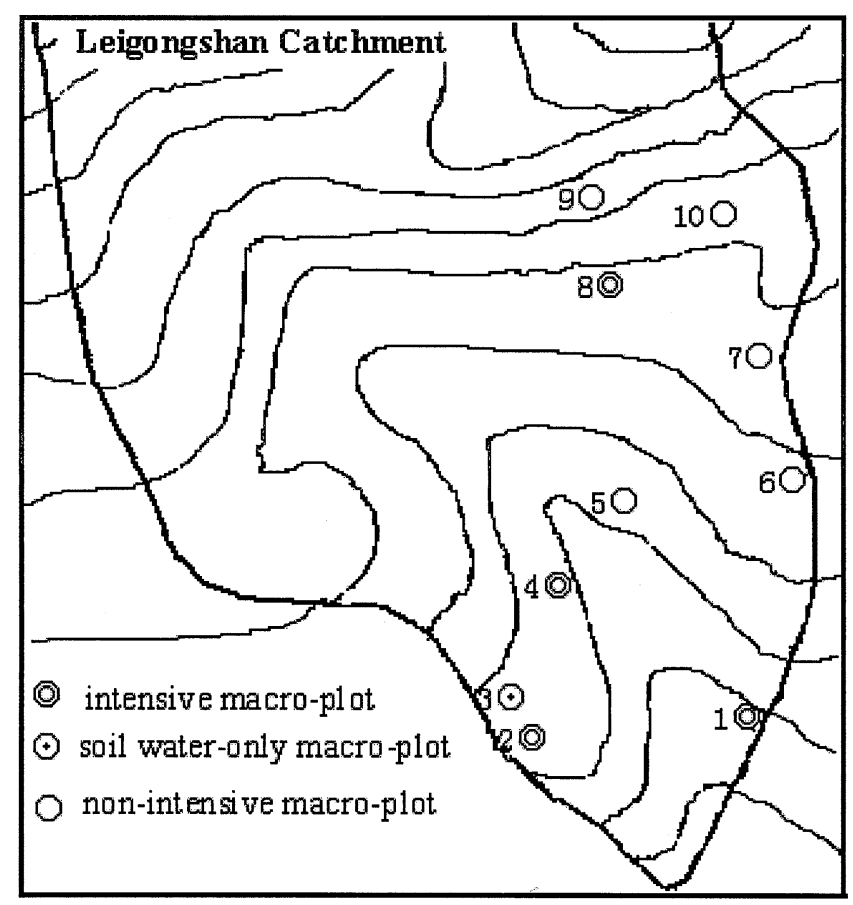

Fig. 1. Map of Leigongshan (LGS) catchment. LGS = Leigongshan

\section{Batch Experiment}

An artificial acidic solution was prepared by diluting hydrochloric acid to $\mathrm{pH}$ of approximately 3.42 . This $\mathrm{H}^{+}$concentration is nearly four times higher than the average value in precipitation in areas in China receiving heavy loads of acid rain (i.e., $\mathrm{pH} 4.1$ to 4.2). The high concentration was chosen to accelerate aluminium release processes to make the changes clearer. Furthermore, the acid solution used in this experiment contained only $\mathrm{HCl}$ instead of $\mathrm{H}_{2} \mathrm{SO}_{4}$, which is typical for acid rain. This was done to avoid the disturbance of coadsorption between aluminium and sulfate on the soil as well as complexation between aluminium and sulfate. 


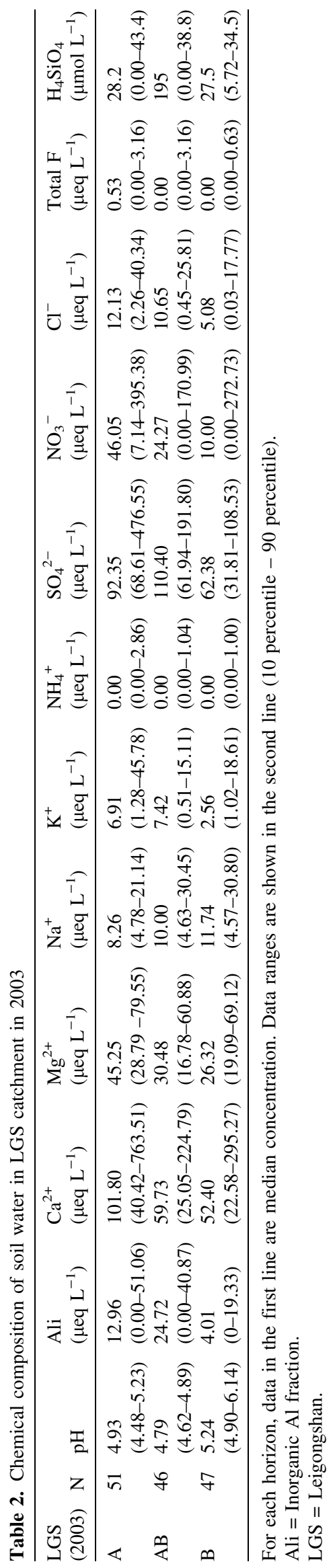

The soils used in the batch experiment were air dried and passed through a $2.0-\mathrm{mm}$ sieve. The samples, $150 \mathrm{~g}$, were then mixed thoroughly before they were evenly divided into 10 subsamples. Each subsample was transferred to a $250-\mathrm{mL}$ Erlenmeyer bottle. The 10 subsamples were extracted with the acid $(\mathrm{HCl})$ solution, the first sample just once, the second twice, and so on until the last sample had been extracted 10 times. Acid solution, $150 \mathrm{~mL}$, was used in each extraction. The slurry was shaken for 30 minutes every 4 hours for 2 days. This shaking time was assumed sufficient to reach equilibrium because it is considerably longer than time shaken in other soil experiments found in the literature (e.g., Liao et al. 1998; Zhu et al. 2004). After the last acidification of each subsample, the supernatant was decanted, centrifuged, and passed through a $0.45-\mu \mathrm{m}$ filter membrane (Millex-HV Millipore) before it was stocked in a polyethylene bottle for chemical analysis. Soil sediments were washed using $500 \mathrm{~mL}$ ion-exchanged water, dried at $40^{\circ} \mathrm{C}$, and stored to measure soil parameters.

\section{Analytic Methods}

$\mathrm{pH}$ values in soil solutions were measured potentiometrically by a $\mathrm{pH}$ combination electrode (Rex E-201-C-9, Rex, Shanghai). Major anions $\left(\mathrm{SO}_{4}{ }^{2-}, \mathrm{NO}_{3}{ }^{-}, \mathrm{Cl}^{-}, \mathrm{F}^{-}\right)$and cations $\left(\mathrm{Ca}^{2+}, \mathrm{Mg}^{2+}, \mathrm{K}^{+}, \mathrm{Na}^{+}, \mathrm{NH}_{4}^{+}\right)$were determined by ion chromatography (Dionex DX 120 with IonPac AS14A and CS12 columns, Dionex, America). Silicon in the leachates was analyzed by a molybdosilicate colorimetric method (Goltermann et al. 1978). Organic matter anion was detected using colorimetric method at $253.7 \mathrm{~nm}$ (McMurry 1990). In most samples, the concentrations were near $0 \mathrm{mg} \mathrm{C} / \mathrm{L}$. The monomeric fraction of aluminium (Ala) was determined using the 8-hydroxy-quinoline method (Barnes 1975). The organic fraction (Alo) of the Ala was determined by first passing the sample through an Amberlight IR-120, Amberlight, Germany cation exchange column. The inorganic Al fraction (Ali) was calculated as the difference between Ala and Alo (Driscoll 1984). The concentrations of different Al species were calculated from Ali using the computer program Alchemi (Schecher and Driscoll 1987). For the samples from the laboratory experiment, the temperature was assumed constant at $20^{\circ} \mathrm{C}$, whereas for the field samples the speciation was conducted using field soil temperatures.

The soil $\mathrm{pH}$ values were determined by mixing 5-g soil sample with $25 \mathrm{~mL}$ deionized water and shaking for 30 minutes. The effective cation-exchange capacity $\left(\mathrm{CEC}_{\mathrm{E}}\right)$ was measured at soil $\mathrm{pH}$ using the $\mathrm{BaCl}_{2}$ extraction method (Hendershot and Duquette 1986). Extractants-0.1 $\mathrm{M} \mathrm{Na}_{4} \mathrm{P}_{2} \mathrm{O}_{7}, 0.1 \mathrm{M} \mathrm{BaCl}_{2}$, and $0.5 \mathrm{M} \mathrm{CuCl}_{2}$ - were used to determine the strongly organically bound (Alp) and exchangeable (Alex) and weakly organically bound (Alcu) aluminium, respectively (McKeague 1967; Hendershot and Duquette 1986; McKeague and Day 1966; Jou and Kamparth 1979; Kaiser and Zech 1996). Metal cations in the extracts were determined using inductively coupled plasma-atomic emission spectrometry. $\mathrm{H}^{+}$activity was determined using a pH combination electrode (Rex E-201-C-9, Rex, Shanghai). Soil organic matter was analyzed using the $\mathrm{K}_{2} \mathrm{CrO}_{7}$ oxidization method (Anonymous 1998).

\section{Results and Discussion}

\section{Aqueous Chemistry}

The distributions of cations in experimental extracts were quite different for the three soil horizons studied. The equivalent charges of the cations in the extracts were divided into three fractions: $\mathrm{H}^{+}$, the equivalent charge of $\mathrm{Al}$ species (Aleq), and base cation $\left(\mathrm{BC}=\right.$ the sum of $\mathrm{Ca}, \mathrm{Mg}, \mathrm{Na}, \mathrm{K}$, and $\left.\mathrm{NH}_{4}\right)$. $\mathrm{BC}$ 
was the dominating cation fraction in all extracts from the A-horizon, whereas equivalent aluminium (Aleq) was less important (percentage $<25 \%$ ). In the extracts from the AB- and B-horizons, Aleq was the main cation fraction and increased with extraction time. Aleq represented $55 \%$ and $66 \%$ in the last extracts, respectively (Fig. 2).

Concentrations in field soil-water were, as expected, lower than in extracts in the laboratory experiment because the mobile anion $\left(\mathrm{Cl}^{-}\right)$concentration in experiment was much higher than the anion concentration in field soil-water. In all field soil-water samples, Ali concentration was lower compared with BCs (median percentage $7.05 \%, 18.5 \%$, and $6.67 \%$ for A-, AB- and B-horizons, respectively [Table 2]).

At present, BCs dominate in soil solution in all three horizons. However, it does not necessarily mean that significant aluminium mobilization will not occur in the short term. In other Chinese regions with higher sulfur loading, such as Guizhou and Chongqing, soil waters with high aluminium and considerable BCs are quite common (Larssen et al. 1998; Zhao et al. 2001). According to the concepts described by Ruess and Johnson (1986), high sulfur deposition can cause aluminium mobilization at higher soil-base saturation. Sulfur deposition fluxes in the LGS area were $0.7,1.1$, and $1.2 \mathrm{~g} \mathrm{~S} \mathrm{~m}^{-2} \mathrm{yr}^{-1}$, and annual volume-weighted $\mathrm{pHs}$ of precipitation were 5.17, 4.97, and 4.44 in 2001, 2002, and 2003, respectively (IMPACTS, unpublished data). Therefore, the worsening acid deposition probably will cause aluminium mobilization in the near future.

\section{Soil Aluminium Release}

Soil aluminium pools are important sources of aqueous aluminium in acidified soils. Figure 3 shows that different pools have different change during acidification extraction. After sequential acidification extractions, strongly organically bound aluminium (Alp-Alcu) decreased in all three soil horizons (i.e., $\mathrm{A}-, \mathrm{AB}-$, and $\mathrm{B}-$ horizons). $\mathrm{CuCl}_{2}$-extractable aluminiums (Alcu) were not significantly larger than Alex, especially in Ahorizon soil. Moreover, no clear change was observed in weakly organically bound aluminium (Alcu-Alex) in three soil horizons during 10 extractions. Compared with the decreases in Alp-Alcu, Alex increased in three soil horizons, indicating that part of aluminium released from the Alp-Alcu pool was adsorbed on soil-exchanging sites, especially in soils with higher BS. These results agree with similar studies in northern Europe and China (Mulder et al. 1989; Mulder and Stein 1994; Zhu et al. 2004). Aluminium budgets between solid soils and solutions are listed in Table 3. Accumulative aluminiums dissolved in solutions are higher than accumulative aluminiums released from solid soils after 5 and 10 acidification extractions, which should be attributed to some undetermined aluminium pools in soil. Zhu et al. (2004) found that acidic oxalate-extractable aluminium (Alex) was also an important contributor to aqueous aluminium in some acidified soils.

Considering the changes both in experimental solutions and in aluminium pools, we conclude that Alp-Alcu is the important source of aqueous aluminium and that Alex plays a significant role in regulating aluminium in soil water. In soils with higher $\mathrm{BS}$, most of the dissolved $\mathrm{Al}$ exchanges with $\mathrm{BC}$ on the soil complex, whereas in soils with lower BS, dissolved $\mathrm{Al}$ remains in solution.

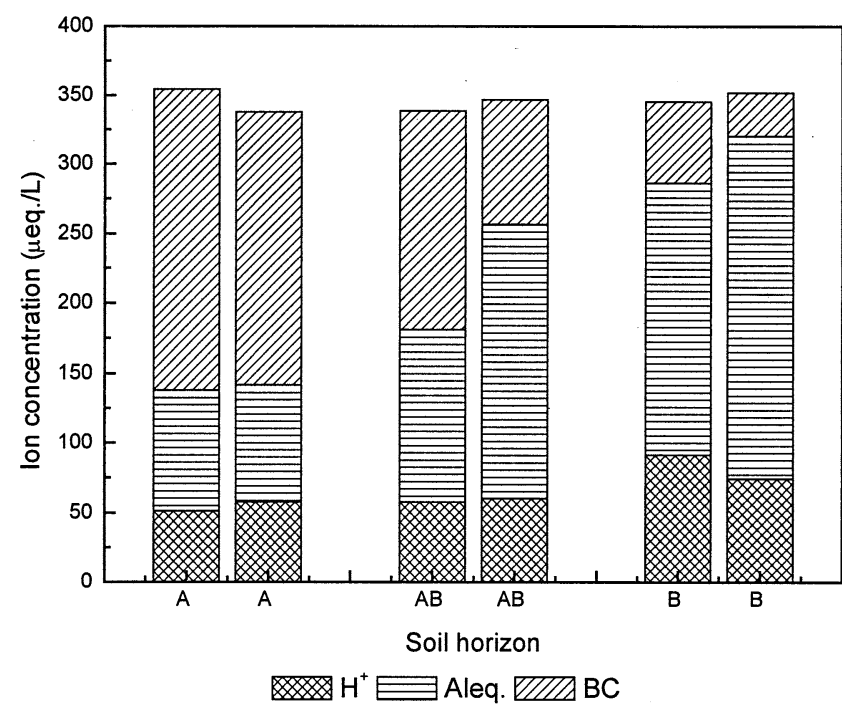

Fig. 2. The changes in cations in extracts after 5 and 10 extractions: for each horizon, left bar is the extracts after 5 extractions; right bar is the extracts after 10 extractions

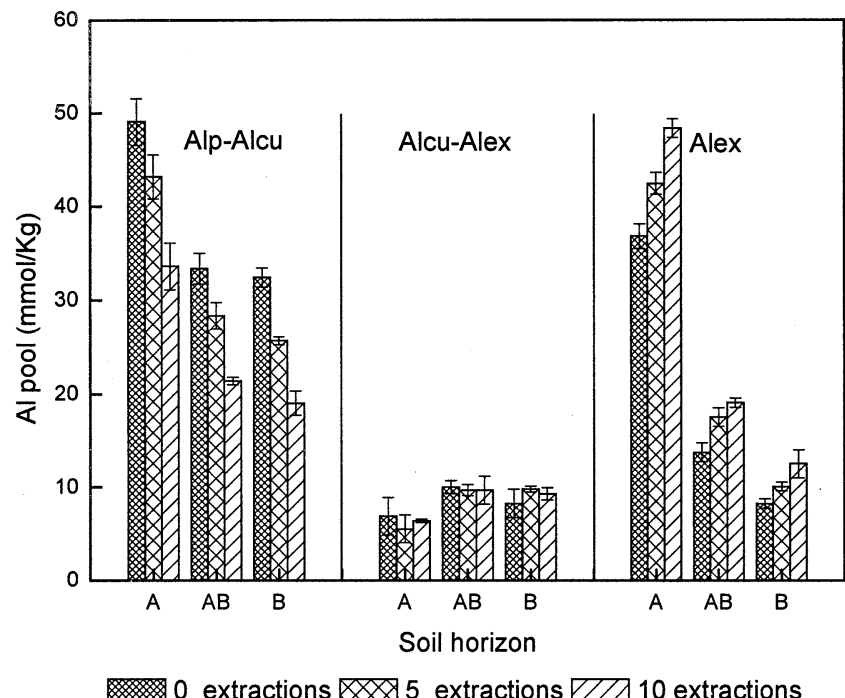

Fig. 3. The change in aluminium pools after 0,5 and 10 extractions

\section{Possible Processes Controlling Aluminium Activity}

Theoretical review. Many models commonly used for soil and soil-water acidification assume that $\mathrm{Al}$ activities in soil solution are in equilibrium with a gibbsite-like $\left(\mathrm{Al}(\mathrm{OH})_{3}\right)$ phase (Tiktak and Van Grinsven 1995). Such equilibriums with gibbsite phase can be expressed as:

$\mathrm{Al}(\mathrm{OH})_{3}(s)+3 \mathrm{H}^{+}=\mathrm{Al} l^{3+}+3 \mathrm{H}_{2} \mathrm{O}$

$\log \left\{A l^{3+}\right\}=\log K s p-3 p H$

where \{\} denotes activity in solution, and Ksp is the solubility product of the gibbsite phase. 
Table 3. Accumulative aluminium released from solid soil and accumulative aluminium in solution

\begin{tabular}{|c|c|c|c|c|}
\hline \multirow[b]{2}{*}{ Soil horizon } & \multicolumn{2}{|c|}{ Al released from solid soil $(\mathrm{mmol} / \mathrm{kg})$} & \multicolumn{2}{|c|}{ Dissolved $\mathrm{Al}$ in solution $(\mathrm{mmol} / \mathrm{kg})$} \\
\hline & 5 extractions & 10 extractions & 5 extractions & 10 extractions \\
\hline A & 1.58 & 4.36 & 2.84 & 4.91 \\
\hline $\mathrm{AB}$ & 1.69 & 6.00 & 1.84 & 6.96 \\
\hline $\mathrm{B}$ & 3.38 & 8.11 & 3.44 & 8.26 \\
\hline
\end{tabular}

Instead, several investigators have postulated that the complexation reaction between $\mathrm{H}^{+}$and aluminium bound to soil organic matter is the dominating process controlling $\mathrm{Al}$ activities in soil-waters (Mulder and Stein 1994; Berggren and Mulder 1995):

$$
\begin{aligned}
& R A l^{(3-x)+}(s)+x H^{+}=R H_{x}(s)+A l^{3+} \\
& \left\{A l^{3+}\right\} /\left\{H^{+}\right\}^{x}=K_{\text {org }} R A l^{(3-x)+} / R H_{x} \\
& \left(R A l^{(3-x)+}\right) /\left(R H_{x}\right) \approx A l_{\text {org }} / C \\
& p Y=p K *_{\text {org }}+x p H,
\end{aligned}
$$

where $\mathrm{pY}=\mathrm{p}\left(\left\{\mathrm{Al}^{3+}\right\} \mathrm{C} / \mathrm{Al}_{\text {org }}\right)$

In the previously mentioned equations, $\left(\mathrm{RAl}^{(3-\mathrm{x})+}\right)$ and $\left(\mathrm{RH}_{\mathrm{x}}\right)$ denote the activities of aluminium and protons bound to soil organic matter, and $\mathrm{K}_{\mathrm{org}}$ represents the equilibrium constant. In practice, the activity ratio $\mathrm{RAl}^{(3-\mathrm{x})+} / \mathrm{RH}_{\mathrm{x}}$ is assumed to be proportional to the ratio between an extractable organically bound aluminium pool (e.g., Alp or Alcu) and the organic carbon content of soil (i.e., $\mathrm{Al}_{\text {org }} / \mathrm{C}$ ) because the number of total and aluminium-occupied binding sites at soil organic matter is difficult to assess.As discussed in a previous section of this article, Alex plays an important role in regulating the aluminium in solution. Here we investigate the possible use of Alex to predict the aluminium activity in soil water in Chinese acidic forest soils. $\left(\mathrm{RAl}^{(3-\mathrm{x})+}\right) /\left(\mathrm{RH}_{\mathrm{x}}\right)$ is assumed to be assumed to be proportional to the ratio between Alex and soil cation exchange capacity $\left(\mathrm{CEC}_{\mathrm{E}}\right)$ instead of $\mathrm{Al}_{\mathrm{org}} / \mathrm{C}$ in the following equation:

$$
\left(R A l^{(3-x)+}\right) /\left(R H_{x}\right) \approx A l e x / C E C_{E}
$$

If $p Y=p\left(A l^{3+} * C E C_{E} /\right.$ Alex $)$

$$
P Y=x p H+p K e x \text {. }
$$

In Equation $7,\left(\mathrm{CEC}_{\mathrm{E}} / \mathrm{Alex}\right)$ is inverse of soil aluminium saturation (AlS) and conceptually related with soil acidity. Therefore, using Equation 8 can reflect the influence of soil acidity on aluminium mobilization.

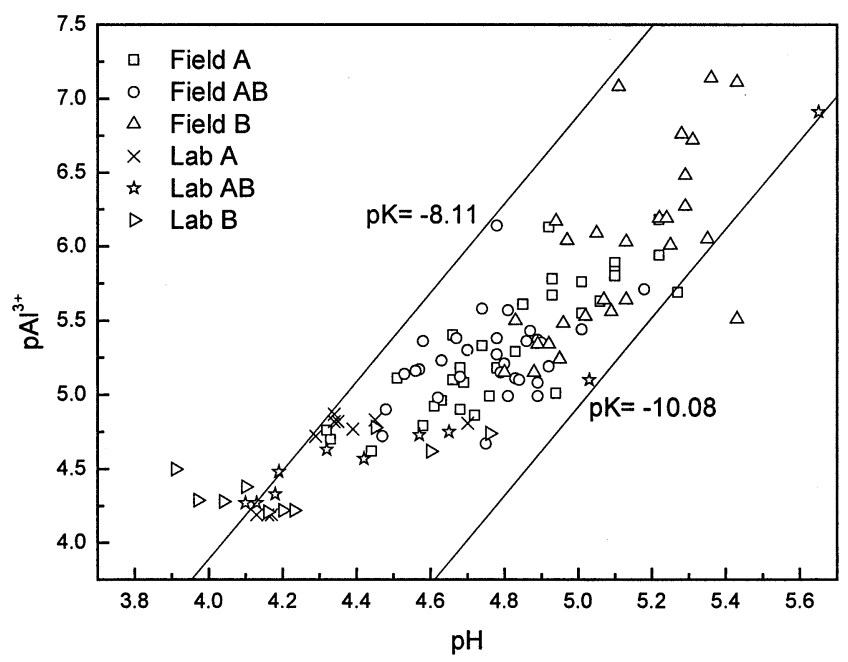

Fig. 4. pH-pAl relationship for experimental and field samples

Gibbsite Dissolution Equilibrium and $p A l-p H$ Relationship. $\mathrm{pAl}-\mathrm{pH}$ diagrams for both experimental and field data are shown in Figure 4. For comparison, equilibrium lines for crystalline gibbsite $\left(\mathrm{Ksp}=10^{8.11}\right)$ and amorphous aluminium trihydroxide $\left(\mathrm{Ksp}=10^{10.08}\right)$ are included ( $\mathrm{Ksp}$ values from Schecher and Driscoll 1987). As found elsewhere, both field and experimental data deviated from the gibbsite equilibrium. $\mathrm{Al}^{3+}$ activities were oversaturated with respect to synthetic gibbsite except for some samples with $\mathrm{pH}<4.2$, whereas the gibbsite model, with respect to amorphous gibbsite (with pKsp $=-10.08$ ) overestimated $\mathrm{Al}^{3+}$ activities in nearly all the samples. The saturation index (SI) with respect to the gibbsite minerals tended to increase with $\mathrm{pH}$.

In some literature, empirical fitted equations and constants have been used to minimize the discrepancies between modelcalculated Al activities in situ or laboratory values. Such an empirical model, described by Reuss et al. (1990), gave satisfactory agreement to both experimental and field data (Table 4). Larssen et al. (1999b) presented pK values optimized for the Chinese soils they studied $(\mathrm{pK}=-9.01)$. However, such empirically fitted constants and equations are known to show large spatial variation and are therefore of limited value in different regions.

SOM-Al model. In Figures $5 \mathrm{a}$ and 5b, data are plotted according to the SOM-Al model (Equation 6) using both Alp and Alcu. Results of linear regressions are listed in Table 4. The SOM-Al model fitted both experimental and field data 
Table 4. Linear regression and model test results of different equilibriums

\begin{tabular}{|c|c|c|c|c|c|c|}
\hline Data & Model & $n$ & Intercept, pK & Slope $\mathrm{x}$ & $R^{2}$ & $p^{\mathrm{a}}$ \\
\hline \multirow[t]{6}{*}{ Experimental data } & Gibbsite $\mathrm{pK}=-8.11$ & 30 & & & & 18.41 \\
\hline & Gibbsite $\mathrm{pK}=-10.8$ & 30 & & & & 38.53 \\
\hline & Empirical pAl-pH & 30 & $-1.02( \pm 0.46)$ & $1.29( \pm 0.10)$ & 0.78 & 5.27 \\
\hline & SOM-Al with Alcu & 30 & $-2.29( \pm 0.64)$ & $1.13( \pm 0.15)$ & 0.68 & 14.6 \\
\hline & SOM-Al with Alp & 30 & $-1.63( \pm 0.69)$ & $1.11( \pm 0.16)$ & 0.64 & 6.40 \\
\hline & SOM-Al with Alex & 30 & $-0.90( \pm 0.58)$ & $1.24( \pm 0.13)$ & 0.76 & 5.87 \\
\hline \multirow[t]{6}{*}{ Field data } & Gibbsite $\mathrm{pK}=-8.11$ & 100 & & & & 29.34 \\
\hline & Gibbsite $\mathrm{pK}=-10.08$ & 100 & & & & 19.25 \\
\hline & Empirical pAl-pH & 100 & $-2.75( \pm 0.63)$ & $1.69( \pm 0.13)$ & 0.64 & 6.74 \\
\hline & SOM-Al with Alcu & 100 & $-5.86( \pm 0.69)$ & $1.85( \pm 0.18)$ & 0.52 & 15.46 \\
\hline & SOM-Al with Alp & 100 & $-6.13( \pm 0.97)$ & $2.01( \pm 0.20)$ & 0.51 & 10.72 \\
\hline & SOM-Al with Alex & 100 & $-3.33( \pm 0.66)$ & $1.76( \pm 0.14)$ & 0.64 & 7.65 \\
\hline \multirow[t]{3}{*}{ Data in Reference } & Wesselink et al. $1996\left(\mathrm{Al}_{\mathrm{p}}\right)$ & 29 & $-2.09( \pm 0.40)$ & $1.19( \pm 0.10)$ & 0.87 & \\
\hline & Larssen et al. $1999 \mathrm{~b}\left(\mathrm{Al}_{\mathrm{p}}\right)$ & 119 & $-2.95( \pm 0.56)$ & $1.42( \pm 0.11)$ & 0.60 & \\
\hline & Larssen et al. $1999 \mathrm{~b}\left(\mathrm{Al}_{\mathrm{Cu}}\right)$ & 119 & $-3.46( \pm 0.56)$ & $1.45( \pm 0.10)$ & 0.63 & \\
\hline
\end{tabular}

${ }^{\mathrm{a}} p$ is defined as: $\left(\left[\sum\left(\mathrm{pAl}_{\text {measured }}-\mathrm{pAl}_{\text {modelled }}\right)^{2} /(\mathrm{n}-2)\right]^{1 / 2}\right) / \mathrm{pAl}$ avg.measured $* 100 \% . n$ denotes the number of samples. Lower $p$ values indicate better fits.

Alcn = Weakly organically bound aluminium.

Alex $=$ Exchangeable aluminium.

Alp $=$ Strongly organically bound aluminium.

better than the gibbsite model (Fig. 4), whereas modeling results using Alp and Alcu were not significantly different. Although $R^{2}$ for Alcu was slightly higher than for Alp, relative standard deviations $(p)$ indicated that the SOM-Al model using Alp predicts $\mathrm{Al}^{3+}$ activities somewhat better than Alcu (Table 4). Results for experimental data were slightly better than for field data. The main likely reason is that the field data were from 15 different lysimeters locations, whereas the batch experiment was conducted on only three different soils. Furthermore, the $\mathrm{pH}$ in the soil extracts of the batch experiment was lower than in field-soil water. Studies have suggested that model performances are better at $\mathrm{pH}$ values $<4.3$ (Wesselink et al. 1996). Coefficients in the linear regression equations of the SOM-Al model vary significantly among the results reported by different investigators (Table 4). These deviations may be caused by differences in soil characteristics influencing the Al mobility and not accounted for by differences in the Alp or Alcu pools. The slopes of our linear regression on the batch titration data were low. This is likely because of the high $\mathrm{H}^{+}$inputs, which made the soils more acidic with low $\mathrm{pH}$ and high AlS.

Figure 5c shows diagrams of $\mathrm{pY}-\mathrm{pH}$ according to Equation 8. The fit is clearly better than for the gibbsite model. The deviations between modeled and measured data (in pAl form) are also smaller than for the original SOM-Al model (Table 4). The fit is slightly better for the laboratory data than for the field data as discussed in previous sections. From Table 4, we see that the slopes for both laboratory and field sample were similar to those of empirical $\mathrm{pAl}-\mathrm{pH}$ equations.

SOM-Al models using Alp, Alcu, and Alex gave better fits to laboratory and field samples than did the gibbsite model. One possible reason is the reasonable consideration of differences in soil properties such as soil aluminium pools. However, it is difficult to distinguish the roles of different aluminium pools in aluminium mobilization because of extreme complicity of soil systems. Studies conducted in China and western countries showed that Alp is the important sources and regulator of aqueous aluminium in acidified soils (Mulder et al. 1989; Liao et al. 1998; Zhu et al. 2004). Usually, Alcu was correlated with soil organic carbon (Liao et al. 1998; Lydersen et al. 1997) and has been considered a better measure than Alp to evaluate soil organically bound aluminium (Jou and Kamprath 1979). Larssen et al. (1999) reported the better fits of SOM-Al model using Alcu over Alp in some Chinese acidic soils. In China, especially in southern and southwestern China where the climate is tropical and subtropical, soil organic matter is usually lower than north Europe because of quick decomposition; the roles of organically bound aluminium in controlling aluminium solubility are quite uncertain. Our experimental results showed that Alex can significantly regulate aluminium solubility in soil solution, which also was supported by better fits of SOM-Al models using Alex.

\section{Summary}

Experimental data showed that Alp-Alcu decreased significantly after sequential extraction $(1500 \mathrm{~mL})$, whereas Alex increased in all three horizons. In the A-horizon with higher $\mathrm{BS}$, dissolved aluminium exchanged with BCs on soil complex, thus causing lower aluminium release but significant leaching of BCs. However, in AB- and B-horizon with lower $\mathrm{BS}$, more dissolved aluminium remained in solution. $\mathrm{Al}^{3+}$ activities in experimental soil extracts and field soil-waters strongly deviated from those predicted by the gibbsite model (i.e., $\mathrm{pAl}=\mathrm{pKsp}+3.0 \mathrm{pH}$ ) despite a significant increase in $\mathrm{Al}^{3+}$ with decrease in $\mathrm{pH}$. The soil organic bound aluminium (SOM-Al) model, using Alcu and Alp to account for differences in the size of available Al pools in the soil, gave considerably better fits to both experimental and field data. The SOM-Al model, approved by using Alex instead of organically bound aluminium (i.e., Alp and Alcu), predicted changes in Al 

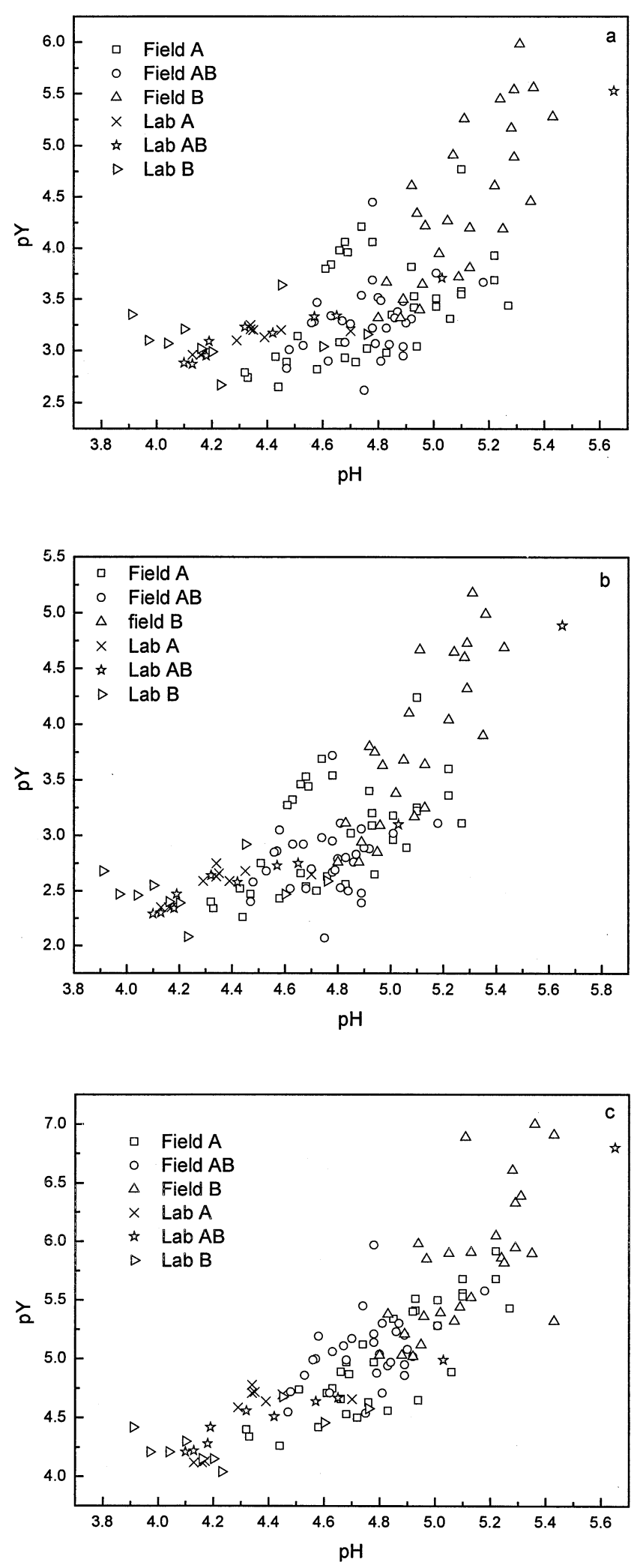

Fig. 5. Diagrams of SOM-Al model. (a) Using Alp. (b) Using Alcu. (c) Using Alex. Alcu = Weakly organically bound aluminium; Alex $=$ exchangeable aluminium; Alp = strongly organically bound aluminium. activities most successfully. We conclude that Alp-Alou is the main source of aqueous aluminium, whereas Alex plays an important role in regulating aluminium solubility during soil acidification.

Acknowledgments. This study was supported by the National Natural Science Foundation of China (No. 40273045;50166001) and National Basic Research Program of China (No. 2005CB422206).

\section{References}

Andersson M (1988) Toxicity and tolerance of aluminium in vascular plants: A literature review. Water Air Soil Pollut 39:439-462

Anonymous(1998) Determination of organic matter in forest soil and calculation of carbon-nitrogen ratio. In: Liu G, (ed) Soil physical and chemical analysis and description of soil profiles. Standard Press of China, Beiing, China, pp 166-167

Barnes RB (1975) The determination of specific forms of aluminium in natural water. Chem Geol 15:177-191

Berggren D, Mulder J (1995) The role of organic matter in controlling aluminium solubility in acidic mineral soil horizons. Geochim Cosmochim Acta 59:4167-4180

Dai Z, Liu Y, Wang X, Zhao D (1998) Decrease in soil pH in southern China within about 30 years. Water Air Soil Pollut 108:181-192

Driscoll CT (1984) A procedure for fraction of aqueous aluminium in dilute acidic waters. Int J Environ Anal Chem 16:267-283

Goltermann HL, Clymo RS, Ohnstad MAM (1978) Methods for physical and chemical analysis of fresh waters, second edition. HBP Handbook Bo.8 Blackwell, Oxford

Hendershot WH, Duquette M (1986) A simple barium chloride method for determining cation exchange capacity and exchangeable cations. Soil Sci Soc Am J 50:605-608

Jou ASR, Kamprath EJ (1979) Copper chloride as an extractant for estimating the potentially reactive aluminium pools in acid soils. Soil Sci Soc Am J 43:35-38

Kaiser K, Zech W (1996) Defects in estimation of aluminium in humus complexes of podzolic soils by pyrophosphate extraction. Soil Sci 161:452-458

Larssen T, Xiong J, Vogt RD, Seip HM, Liao B, Zhao D (1998) Studies of soil, soil water and stream water at small catchment near Guoying, China. Water Air Soil Pollut 10:137-162

Larssen T, Seip HM, Semb A, Mulder J, Muniz IP, Vogt RD, et al. (1999a) Acid deposition and its effects in China: An overview. Environ Sci Pollut 2:9-24

Larssen T, Vogt RD, Seip HM, Furuberg G, Liao B, Xiao J, et al. (1999b) Mechanisms for aluminium release in Chinese acid forest soils. Geoderma 91:65-86

Liao B, Larssen T, Seip HM (1998) Response of two five Chinese forest soils to acid inputs. Batch experiment. Geoderma 86:295316

Lydersen E, Angell V, Eilertsen O, Larssen T, Mulder J, Muniz IP, et al. (1997) Planning of an integrated acidification study and survey on acid rain impacts in China. Final Report to the World Bank. NIVA, Oslo, Sweden

McKeague JA (1967) An evaluation of 0.1 M pyrophosphate and pyrophosphate-dithionite in comparison with oxlate as extractant of accumulation products in podols and some other soils. Can J Soil Sci 47:95-99

McKeague JA, Day JH (1966) Dithionite- and oxlate-extractable Fe and $\mathrm{Al}$ as aids in differentiation various classes of soils. Can J Soil Sci 46:13-22

McMurry J (1990) Fundamental of organic chemistry, 2nd ed. BrookCole, Pacific Grove, CA 
Mulder J, Stein A (1994) solubility of aluminium in acidic forest soils: Long-term changes due to acid deposition. Geochim Cosmochim Acta 58:85-94

Mulder J, Van Breemen N, Eijck HC (1989) Depletion of soil aluminium by acid deposition and implications for acid neutralization. Nature 337:247-249

Pan GX (1992) Acidification of soils in Mount Lucian over the last 35 years. Pedosphere 2:179-182

Reuss JO, Johnson DW (1986) Acid deposition and the acidification of soils and waters. Springer-Verlag, New York, NY, 35-36

Reuss JO, Walthall PM, Roswall EC, Hopper RWE (1990) Aluminium solubility, calcium-aluminium exchange, and $\mathrm{pH}$ in acid forest soils. Soil Sci Soc Am J 54:374-380

Rosseland BO, Eldhuset TD, Staurnes M (1990) Environmental effects of aluminium. Environ Geochem Health 12:17-27

Schecher WD, Driscoll CT (1987) An evaluation of uncertainty associated with aluminum equilibrium calculations. Water Resour Res 23:525-534

Seip HM, Aagaard P, Angell V, Larssen T, Lydersen E, Mulder J, et al. (1999) Acidification in China: Assessment based on studies at forest sites from Chongqing to Guangzhou. Ambio 28:522-528
Tang D, Lydersen E, Seip HM, Angell V, Eilertsen O, Larssen T, et al. (2001) Integrated monitoring program on acidification of Chinese terrestrial systems (IMPACTS) - A Chinese-Norwegian cooperation project. Proceedings of the 6th International conference on acidic deposition. Water Air Soil Pollut 130:10731078

Tiktak A, Van Grinsven HJM (1995) Review of 16 forest-soil-atmosphere models. Ecol Modell 83:35-53

Wesselink LG, Van Breemen N, Mulder J, Janssen PH (1996) A simple model of soil organic matter complexation to predict the solubility of aluminium in acid forest soils. Eur J Soil Sci 47:373384

Zhao D, Larssen T, Zhang Gao Vogt Seip D S RD HM, et al. (2001) Acid deposition and acidification of soil and water in the Tie Shan Ping area, Chongqing, China. Water Air Soil Pollut 130:17331738

Zhu Jiang X, Ji G (2004) Experimental investigation on aluminum release from haplic acrisols in southeastern China. Appl Geochem 196:981-990

Zhu X, Pawlowski L, Kotowski M, Siek A (1994) Mechanisms of aluminium mobilization in soils. J Ecol Chem 3:169-194 